\title{
Study on Air Supply Control of Marine Variable-Air-Volume Air-Conditioning System
}

\author{
Junjie Guo ${ }^{1}$, Xiaoli Meng2* ${ }^{2 *}$ Qiang Ma ${ }^{1}$ \\ ${ }^{1}$ Naval Architecture \& Marine Engineering College, Shandong Jiaotong University, Weihai, China. \\ 2 International Business School, Shandong Jiaotong University, Weihai, China. \\ * Corresponding author. Tel.: 0631-3998932; email: rogerstudent@163.com \\ Manuscript submitted January 24, 2019; accepted March 28, 2019. \\ doi: 10.17706/ijcee.2019.11.2.108-117
}

\begin{abstract}
This study, taking Marine Variable-air-volume Air-conditioning System (VAV A/C system) as a research object, designed experimental platform of VAV A/C system and proposed control strategy of air supply volume of the system. Furthermore, this study carried out a comparative study of two different air supply control methods, namely, controlling static pressure of supply air by control unit of static pressure and by frequency conversion fan. Therefore, change in parameter such as cabin temperature, terminal opening, and operating frequency of compressors and fan, can be investigated under the conditions of cooling, setting cabin temperature and step change of cabin load. The research shows that both control methods can realize satisfactory control over temperature of air-conditioning cabin. What is more, power consumption of the two systems is investigated under the same working condition. Study shows that Marine VAV A/C system whose supply air static pressure is controlled by frequency conversion fan is more energy-saving than that controlled by static pressure control unit.
\end{abstract}

Key words: Marine, variable-air-volume system, supply air, control, energy-saving.

\section{Introduction}

At present, constant air volume (CAV) is widely adopted in marine air-conditioning system. When designing a CAV air-conditioning system, the volume of its refrigeration unit and air-side air regulation device is selected based on condition of maximum load. However, during the voyage, influenced by various factors such as navigation area, navigating course, climate condition, solar radiation angle and the amount of equipment put into use, etc. dynamic thermal loading of the ship changes dramatically, which leads to partial loading of the marine A/C system most of the time, low operation efficiency and remarkable loss of energy [1]. Moreover, sailing at the lower temperature ocean area may cause relatively lower cabin temperature, larger supply air volume and poorer thermal comfort in cabin air [2], [3].Therefore, how to improve the comfort of marine A/C system and meantime save energy, how to realize automatic change in supply air volume of each cabin according to cabin load and further make refrigerating capacity and total air supply volume of the $\mathrm{A} / \mathrm{C}$ system change with variation of air-conditioning load, which is a difficult problem that constant air volume A/C system faces. VAV A/C system is one of the approaches to solving the problem. Researches show that VAV A/C system has significant advantage of saving energy because this system is able to adjust total air supply volume and that of each cabin automatically, reduce energy consumption of the fan, avoid counteracting of cold and heat, and eventually save energy [4]-[6]. However, marine VAV A/C system has characteristics of nonlinear, cultivable, slow time varying and strong coupling 
[7]. Further research needs to be carried out on strategy of system control to realize satisfactory independent control over each zone, control over cabin temperature and energy saving.

At present, many researchers are committed to studies of energy consumption of VAV A/C system. However, these studies focus only on theoretical study of a single control system through the establishment of a mathematical model of the device to study the performance of different strategies. These studies put emphasis on thermal and energy characteristics of static systems. However, the influence of control system on A/C energy consumption is dynamic. Therefore, this study establishes an experimental platform of variable air volume system and carries out systematic analysis of working conditions and energy consumption of VAV A/C system under different control strategies. It aims at providing scientific foundation to choose suitable systems for marine $\mathrm{A} / \mathrm{C}$ designers and promoting application of the system.

\section{Marine VAV A/C System and Supply Air Control}

\subsection{VAV A/C System}

The structural diagram of experimental platform of the VAV A/C system is demonstrated in Fig. 1.

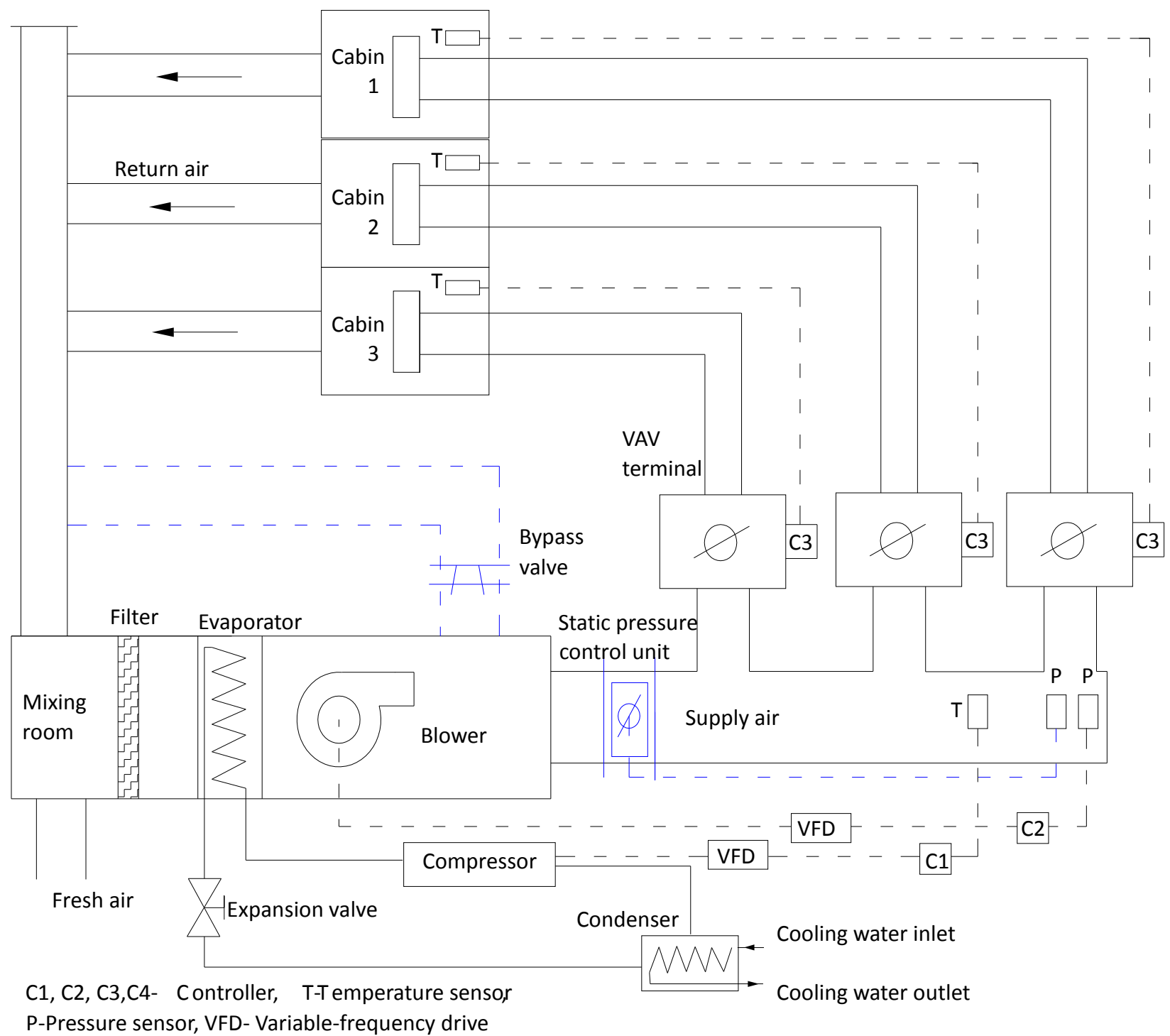

Fig. 1. Structure diagram of marine VAV A/C system. 
This platform is composed of a direct-expansion VAV A/C system and a data acquisition system. VAV A/C system contains devices such as air handling equipment, condensing unit, blower, static pressure control unit, variable air volume terminal, diffuser, temperature controller and air supply controller etc. And data acquisition system includes data acquisition equipment, sensors and central processing unit. In marine VAV A/C system, air-side and refrigeration unit side interact with each other directly without sub-systems of water cycle processing [7]. Furthermore, the adjustment of variable-air-volume terminals is frequent due to the great change of load and total air volume in the marine air-conditioning system. And Control loops of supply air temperature and that of variable-air-volume exert influence on each other. In this system, return air from the air-conditioner and fresh air from outside the room are mixed in the mixing chamber of the air processing box. The mixed air is cooled down and dehumidified through the direct-expansion evaporator. And then it is sent to the air supply pipe by the blower and enters into the air-conditioning cabin through VAV terminals. Each terminal adjusts its own air volume according to air temperature in the air-conditioning zone. Cooling water from the cooling tower arrives at condenser through circulating pump, exchanges heat with refrigerant in the condenser and returns to the cooling tower.

\subsection{Supply Air Control Strategies of Marine VAV A/C System}

Factors such as high coupling of loops, mutual interruption, and intense change of the A/C dynamic thermal loading during voyage in the marine VAV A/C system enlarge the difficulty of supply air control. Therefore, it is hard for PID controller which adopts fixed control parameters to adapt to the variable operating condition of the system in a large range [8], [9]. The control strategy of the system should react to the change of the total supply air volume needed by the system timely and refrigerating capacity of the system should match the changing air-conditioning load precisely to keep a stable supply air temperature. Currently static pressure control and total air volume control are mainly used in VAV A/C system. This research applies air supply temperature control by fixing air supply static pressure. Two control strategies of supply air static pressure are adopted in this research system to investigate operation characteristics and power consumption of marine VAV A/C system under different control method of supply air static pressure. In one strategy, frequency conversion fan is used to control supply air static pressure, while in the other, static pressure control unit and bypass air-valve are adopted.

\subsubsection{Supply air static pressure controlled by frequency conversion fan}

Fig. 1 demonstrates that supply air static pressure controlled by frequency conversion fan is realized by differential pressure sensor, blower controller, frequency converter and frequency conversion fan. When cabin load changes, VAV terminals will adjust opening of air valve and supply air static pressure of air pipe will also change [10]. Supply air static pressure should be kept stable and meantime reaction rate of control should be enhanced to lower static deviation of control in order to reduce mutual interruption among different terminals or air conditioning zone and achieve independent zone control. Stable supply air static pressure of VAV A/C system can be realized by real-time change of supply air volume of the blower. Moreover, air volume of blower is proportional to quadratic of fan revolution. Therefore, frequency converter can be applied to controlling fan revolution and achieve the purpose of supply air static pressure control.

Mechanism of supply air static pressure control by frequency conversion fan is as follows. Static pressure sensors installed on air supply pipe senses the change of supply air static pressure and sends detected signal of static pressure to fan controller. The controller carries out calculation according to the signal and set value and sends control signal to frequency converter. Running frequency of the blower is adjusted under the action of frequency converter and further change of supply air volume and stable supply air static pressure can be realized. In operating, installation and adjustment of the system should be carefully carried 
out to avoid mutual interruption of frequency converter and other electronic equipment to cause fluctuation of the system.

\subsubsection{Supply air static pressure controlled by static pressure control unit}

On condition of blower operating at constant speed and stable supply air volume, control of supply air static pressure can be achieved by changing features of air pipeline. Install regulating valves on supply air main pipe and exert throttle control over regulating valves. Therefore, resistance characteristic curve of supply air main pipe will be changed, further air supply volume will be changed and finally control of supply air static pressure will be realized. This study designed a marine AVA A/C system adopting static pressure control unit to control supply air static pressure. Fig. 1 shows that static pressure control unit is installed on the air supply main pipe and bypass pipe is equipped behind blower exit and in front of static pressure control unit connected with air return pipe.

Mechanism of static pressure control by static pressure control unit is as follows. When supply air static pressure varies, static pressure sensors installed on air supply pipe senses the change of supply air static pressure and sends detected signal to static pressure control unit. Controller of static pressure control unit compares actual value of pipe static pressure and the set value of supply air static pressure, obtain and process the difference value and output control signal to drive air valve motor enlarging or decreasing valve opening of static control unit. Therefore, stability of supply air static pressure can be achieved.

\section{Operating Feature of the System under Two Supply Air Methods}

To compare operating feature of the system under two supply air methods, this study investigates the air quality of each cabin and operating of the system under the conditions of cooling, setting cabin temperature and step change of cabin load. Furthermore, operating stability of VAV A/C system when controlled by two different methods and realization of independent control for each cabin can be tested.

Working condition and parameter setting of the system are as follows. There are three air-conditioning cabins in the system. The initial setting temperature of cabin one is $25.5^{\circ} \mathrm{C}$. The initial setting temperature of cabin two is $25^{\circ} \mathrm{C}$. The initial setting temperature of cabin three is $24.5^{\circ} \mathrm{C}$. And the supply air temperature is set as $14^{\circ} \mathrm{C}$. The system is controlled by two different methods of supply air static pressure with the same working condition and other parameter setting.

When adopting method one and the system has operated for 120 minutes, step change the setting temperature of cabin three from $24.5^{\circ} \mathrm{C}$ to $25.5^{\circ} \mathrm{C}$. When the system has operated for 260 minutes, introduce step disturbance of thermal load to cabin three, i.e. increase thermal load of cabin three by $1 \mathrm{KW}$, as is indicated in Fig. 2-4. Fig. 2-4 demonstrates that when the system starts to operate, the temperature of each cabin decreases sharply and then stabilize at the initial setting temperature with control precision at a range of $\pm 0.5^{\circ} \mathrm{C}$. During cooling of each cabin, terminal valve opening of each cabin varies with cabin temperature. After the system operates 13 minutes, terminal valve opening of cabin three begins to be regulated for minor flow and gradually stabilized. After the system operates 29 and 36 minutes, terminal valve opening of cabin two and one begins to be regulated for minor flow and gradually stabilized. Operating frequency of compressor and blower decreases with cabin load and is finally maintained at a relatively stable range. When setting temperature of cabin three is changed to $25.5^{\circ} \mathrm{C}$, temperature of cabin three begins to rise and is stabilized at $25.5^{\circ} \mathrm{C}$ after 40 minutes with control precision at a range of $\pm 0.3^{\circ} \mathrm{C}$. temperature of the other two cabins fluctuate yet with control precision still at a range of $\pm 0.5^{\circ} \mathrm{C}$. In this situation, terminal valve opening of cabin three begins to be regulated for minor flow, while terminal valve opening of cabin two and one changes little. Since only one terminal valve opening is changed remarkably and gradually stabilized and air volume of the system changes very little, operating frequency of 
compressor and blower are relatively stable. When load of cabin three increases by $1 \mathrm{KW}$, temperature of cabin three varies dramatically yet with control precision at a range of $\pm 0.4^{\circ} \mathrm{C}$ and is gradually stabilized. Temperature of cabin two has no obvious change while that of cabin one fluctuates obviously yet with control precision still at a range of $\pm 0.5^{\circ} \mathrm{C}$. Terminal opening of cabin three increases, while that of cabin two fluctuates and is soon stabilized. Although terminal opening of cabin one changes a lot, it shows a decreasing tendency. When Cabin load is increased, operating frequency of compressor and blower turns higher but stable in general. The above variation results from change of cabin setting temperature and cabin load, which causes air volume needed to change and further brings about change of static pressure of supply air pipe. However, change of supply air static pressure exerts influence on terminal valve opening of other cabins and then cabin temperature. Compressor and blower will also change in order to keep supply air static pressure and supply air temperature stable.

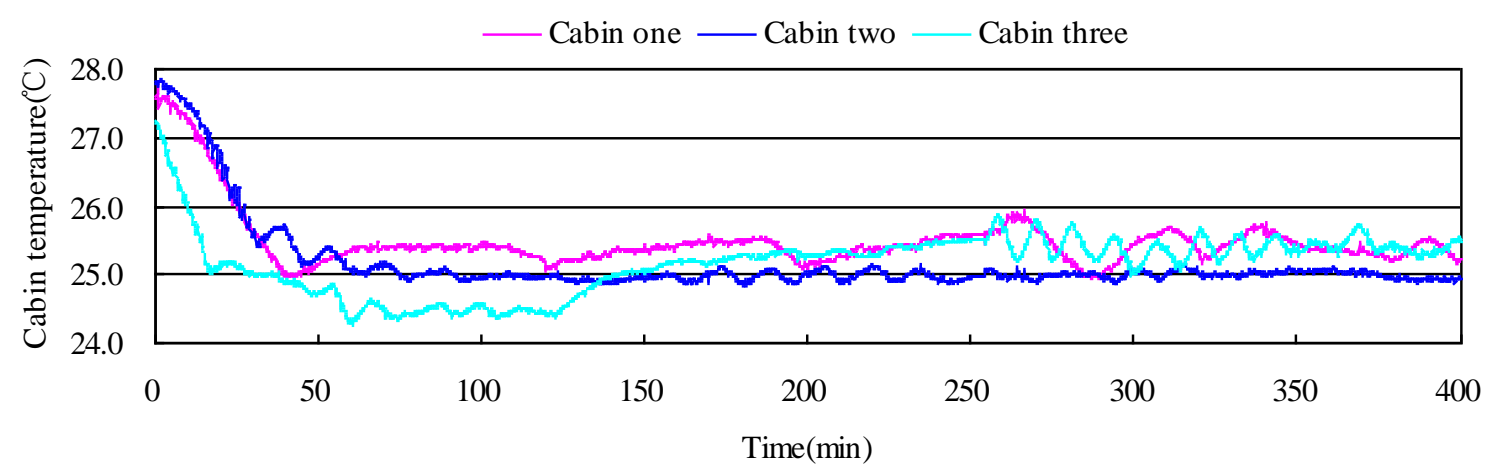

Fig. 2. Method one: Temperature of each cabin.

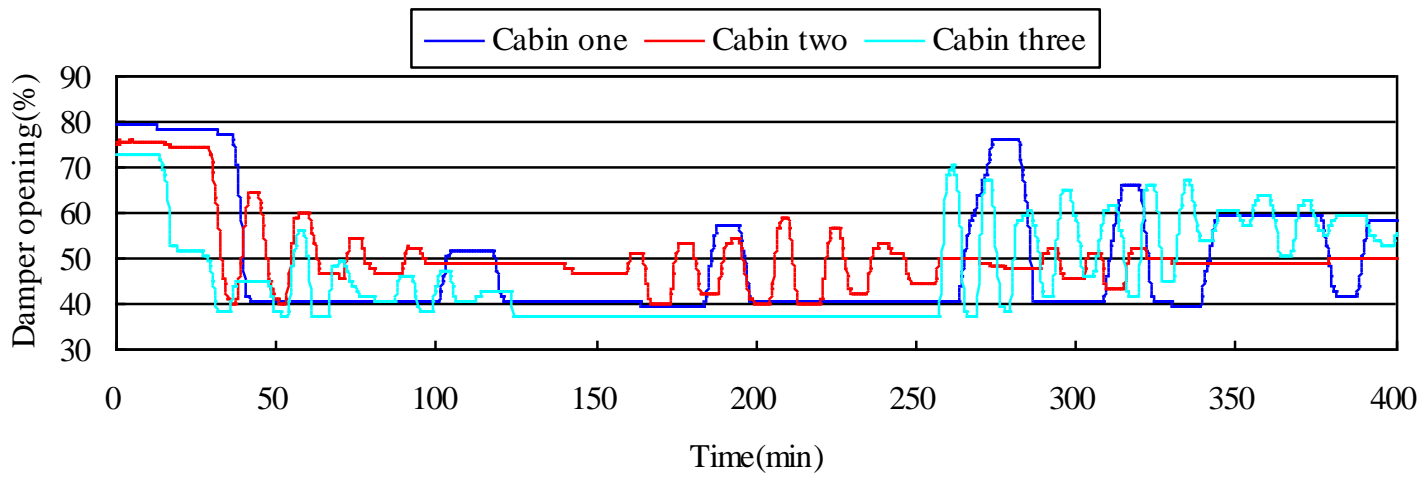

Fig. 3. Method one: Terminal valve opening of each cabin.

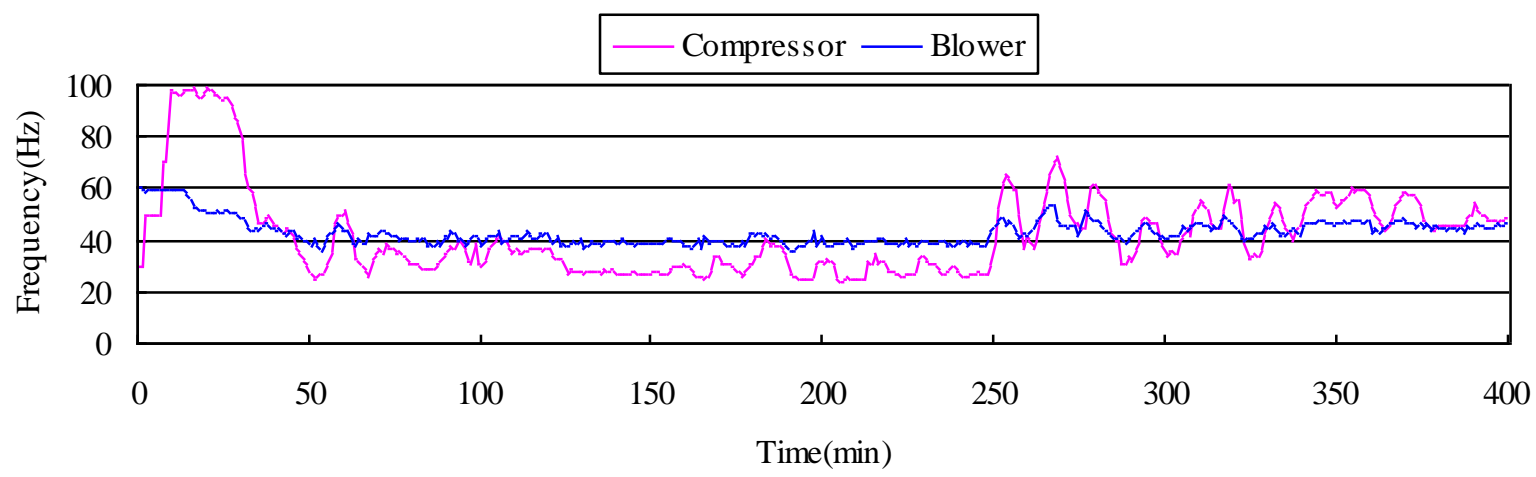

Fig. 4. Method one: Operating frequency of compressor and blower. 
According to analysis, independent control of cabin temperature can be realized when adopting method one. During operation, the system fluctuates slightly due to mutual interference of control loops of static pressure, cabin temperature and terminal but is generally stable.

When adopting method two and the system has operated for 120 minutes, step change the setting temperature of cabin three from $24.5^{\circ} \mathrm{C}$ to $25.5^{\circ} \mathrm{C}$. When the system has operated for 300 minutes, introduce step disturbance of thermal load to cabin three, i.e. increase thermal load of cabin three by $1 \mathrm{KW}$, as is indicated in Fig. 5-7. Fig. 5-7 indicates that the change curve of each cabin temperature is similar to method one and independent control of cabin temperature can be achieved with control precision at a range of $\pm 0.5^{\circ} \mathrm{C}$. The two control methods are also similar judged from variation curve of terminal valve opening and operating frequency of compressor. However, when setting temperature and load of the cabin changes, system adopting method two tend to be stabilized faster than that of method one. The reason is that frequency converter is used to control rotational speed of blower in method one to control supply air static pressure. The high speed of regulation by adopting frequency converter causes rotational speed of blower to change frequently and frequency converter tend to be disturbed by itself ad other electrical equipment, which adds to instability of blower. In method two, static pressure control unit is used to control supply air static pressure. Therefore, the regulation of method two is relatively slower than that of method one, which makes its regulation and change less frequent and improves operating stability of the system.

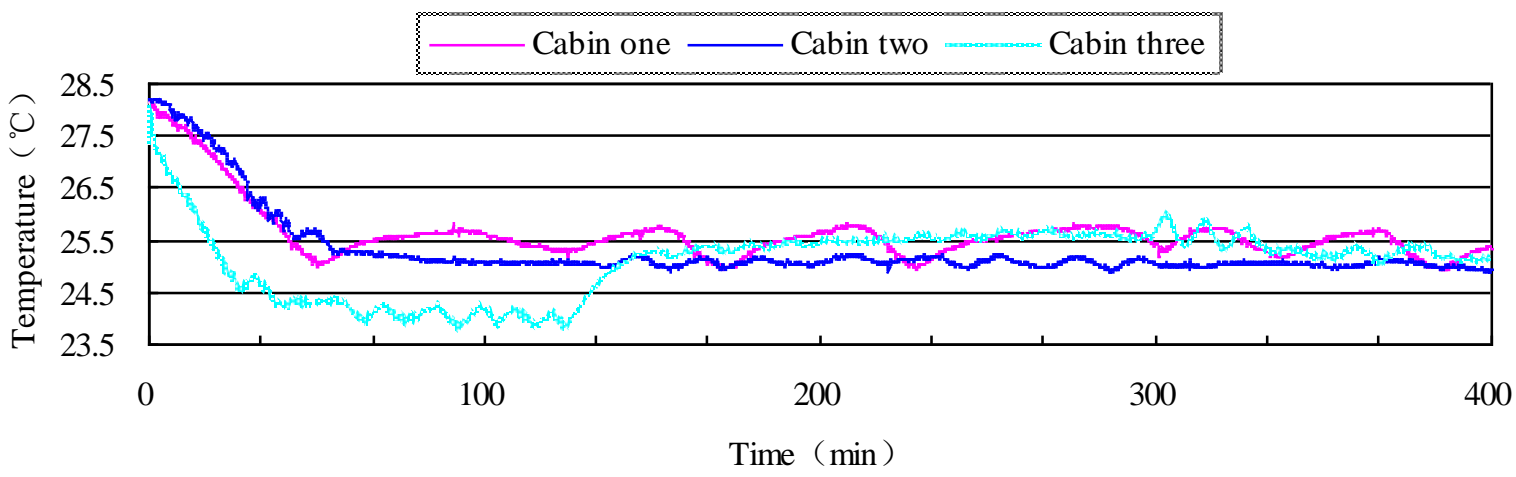

Fig. 5. Method two: Temperature of each cabin.

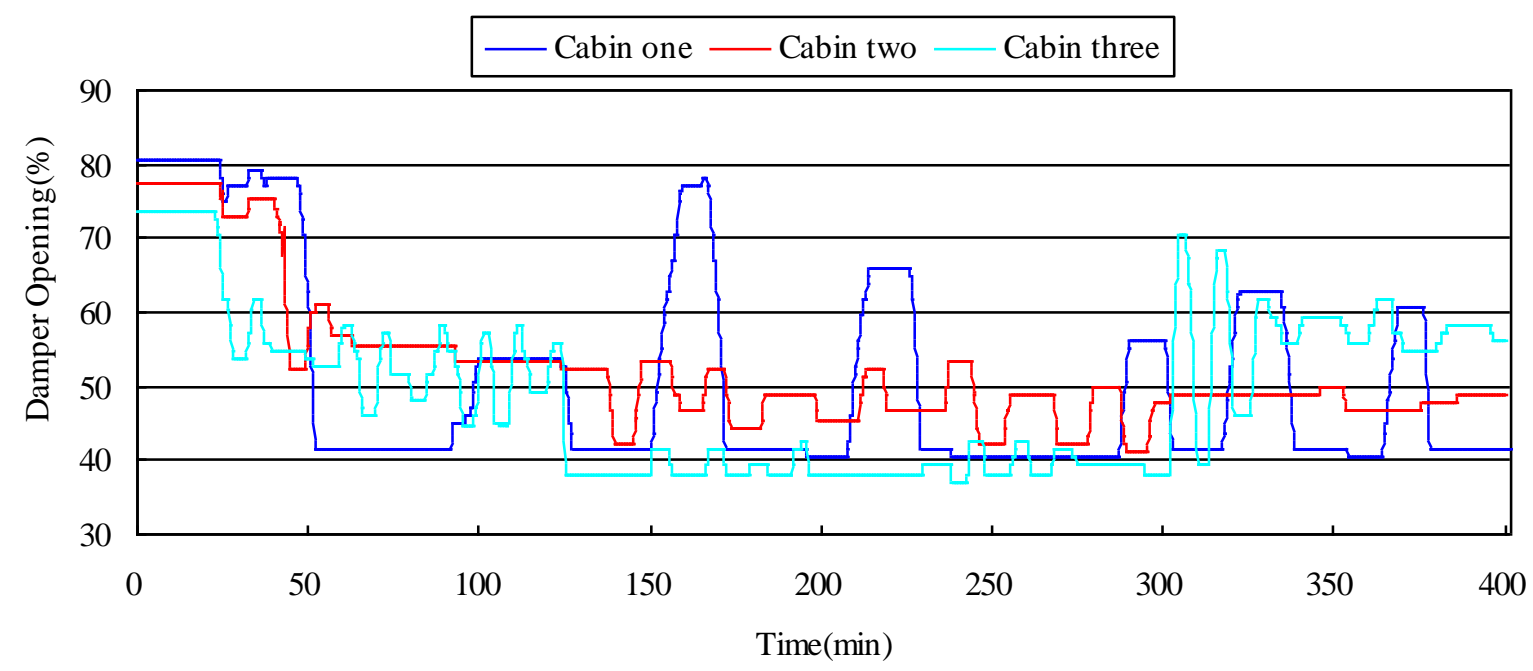

Fig. 6. Method two: Terminal valve opening of each cabin. 


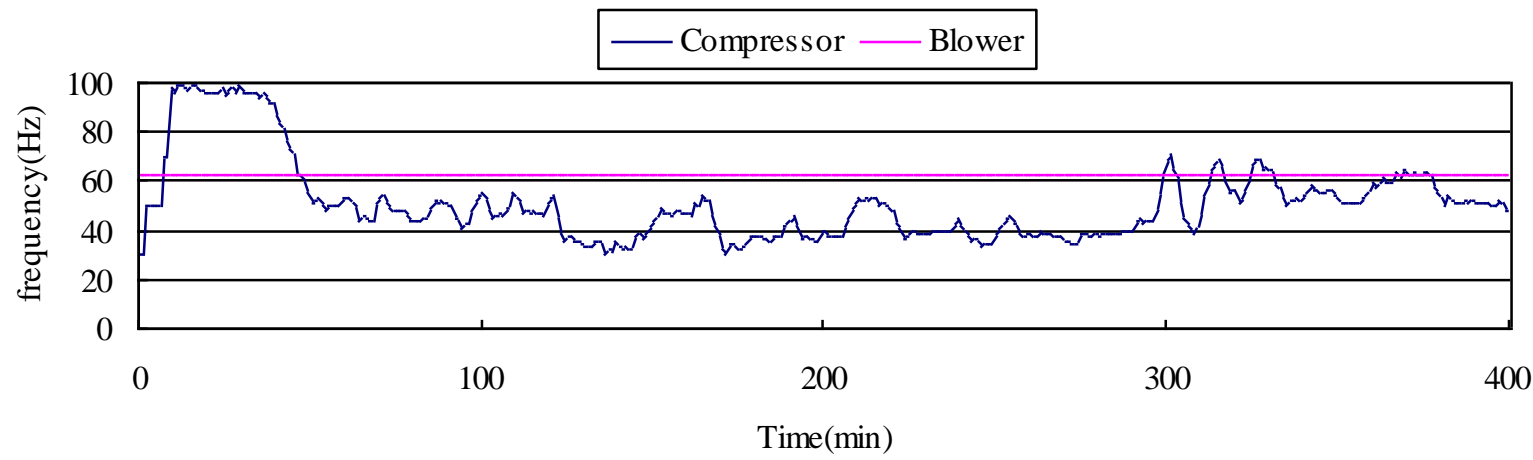

Fig. 7. Method two: Operating frequency of compressor and blower。

\section{Energy Consumption Analysis of the Systems under Two Supply Air Static Control Methods}

Compared with CAV air conditioning system, VAV air conditioning system is more energy-saving, which has been widely recognized by people in the air conditioning industry. When the static control unit was used to control the supply air static pressure, cooled and dehumidified excess air came back to the mixing chamber through the bypass valve, it could reduce the supply air temperature of the windward side of the evaporator, and lower the rotating speed of refrigeration compressor under the condition of constant supply air temperature, thus the goal of saving energy was achieved. When the variable frequency blower was applied to control supply air static pressure, the supply air volume varied according to the change of room load. As the room load was reduced, supply air volume would decrease; meanwhile, energy consumption of the blower and refrigeration compressor decreased thereupon. However, which control method of supply air static pressure is more energy saving, the application of static pressure unit or variable frequency blower needs further study. The main energy-consuming equipments of the system are refrigeration compressor, blower, and circulating pump. While circulating pump, which operates with a fixed displacement mode, consumes the same amount of energy in the two air control strategies. In addition, the results of the experiment showed that the VAV A/C system could achieve good and independent control over air temperature of air conditioning rooms with both of the two control methods. Therefore, in terms of analysis of VAV A/C system energy consumption, only the calculation of energy consumption of the refrigeration compressor and blower would be carried out based on the operation time.

\subsection{Refrigeration Compressor}

For both control strategies of this experimental platform of VAV A/C system, refrigeration compressor operated with variable frequency. At the beginning of system operation, the temperature in the room was higher. Therefore, a larger volume of air was needed and the temperature of supply air was higher. Under the influence of supply air temperature controller, the compressor operated with high frequency and was more energy-consuming. While as the temperature in the room decreased and a smaller supply air volume was needed, the compressor operated with lower frequency and its energy consumption thereupon decreased, too. Comparison of Energy consumption of the refrigeration compressor with the two methods is showed in Table 1.

As is indicated in Table 1, when the system operated for 30 minutes, system power consumption of the first method equals $85.8 \%$ that of the second method. When the system operated for 120 minutes, the ratio is $95.5 \%$. During other periods, this proportion fluctuates between $85.8 \%$ and $95.5 \%$. Therefore, power consumption of the refrigeration compressor under two static pressure control strategies makes no 
remarkable difference.

Table 1. Energy Consumption of Refrigeration Compressor

\begin{tabular}{ccccccccc}
\hline Time (min) & 15 & 30 & 45 & 60 & 75 & 90 & 105 & 120 \\
\hline $\begin{array}{c}\text { Energy Consumption of } \\
\text { method One (KWh) }\end{array}$ & 0.5788 & 1.0448 & 1.3263 & 1.4958 & 1.7515 & 1.9868 & 2.190 & 2.4230 \\
$\begin{array}{c}\text { Energy Consumption of } \\
\text { Method Two (KWh) }\end{array}$ & 0.6152 & 1.2178 & 1.5441 & 1.7419 & 1.9490 & 2.1523 & 2.3411 & 2.5365 \\
$\quad \begin{array}{c}\text { Energy Consumption } \\
\text { Ratio of Two Methods } \\
(\%)\end{array}$ & 94.1 & 85.8 & 85.9 & 85.9 & 89.9 & 92.3 & 93.5 & 95.5 \\
$\quad$ & & & & & & & & \\
\hline
\end{tabular}

\subsection{Blower}

When the static pressure control unit was applied to control supply air static pressure, the blower was operated at a constant speed with its frequency set as $62 \mathrm{~Hz}$. When variable frequency blower was used to control supply air static pressure, the blower was operated with variable frequency. Its maximum operating frequency was set as $65 \mathrm{~Hz}$. In addition, the opening of bypass air valve was set as $20^{\circ}$. According to study of this aspect, Blower operated with variable frequency could significantly reduce energy consumption compared with that operated at a constant speed. The power which could be saved consists of two parts, one is the power of the valve throttle loss; the other is saved by the blower itself due to the reduced pressure head which results from variable blower speed as well as the improvement of operational efficiency [11]. When the supply air static pressure was controlled by the variable frequency blower, the blower ran with higher frequencies in the beginning. However, with the extension of time, the air conditioning system ran under part load operation for quite a long time. During this time the blower operates in lower frequency, therefore, energy consumption of blower was decreased. The energy consumption of the blower for method 1 and method 2 is shown in Table 2.

Table 2. Energy Consumption of Blower

\begin{tabular}{|c|c|c|c|c|c|c|c|c|}
\hline Time (min) & 15 & 30 & 45 & 60 & 75 & 90 & 105 & 120 \\
\hline $\begin{array}{c}\text { Energy Consumption of method } \\
\text { One (KWh) }\end{array}$ & 0.2096 & 0.3424 & 0.4368 & 0.5283 & 0.6229 & 0.7149 & 0.8046 & 0.8963 \\
\hline $\begin{array}{c}\text { Energy Consumption of Method } \\
\text { Two (KWh) }\end{array}$ & 0.2916 & 0.5160 & 0.7030 & 0.8803 & 1.0588 & 1.2412 & 1.4116 & 1.5920 \\
\hline $\begin{array}{c}\text { Energy Consumption Ratio of } \\
\text { Two Methods (\%) }\end{array}$ & 71.9 & 66.4 & 62.1 & 60.0 & 58.8 & 57.6 & 57.0 & 56.3 \\
\hline
\end{tabular}

As is presented in Table 2, when VAV air conditioning system operated for 15 minutes, power consumption of the blower for the first method is $71.9 \%$ that for the second method. Then with the extension of operation time, this ratio gradually decreased and the energy-saving effect became more and more remarkable. As VAV air conditioning system operated for 120 minutes, the power consumption ratio was $56.3 \%$. It can be seen that the blower power consumption of the two static pressure control strategies vary greatly, when the variable frequency blower was used to control the supply air static pressure, the energy consumption of the blower for a VAV air conditioning was significantly reduced.

\section{Conclusion}

This study built an experimental platform of marine VAV A/C system and made comparison of operation characteristics of the system whose supply air static pressure is controlled by frequency conversion fan and static pressure control unit. Result shows independent control of cabin temperature can be realized by both of the two control methods. When step disturbance of cabin setting temperature and cabin load is introduced, cabin temperature will fluctuate yet still with control precision at a range of $\pm 0.5^{\circ} \mathrm{C}$. From 
perspective of system stability, when cabin setting temperature and cabin load vary, the system adopting frequency conversion fan to control supply air static pressure tend to be stabilized faster than that adopting static pressure control unit. In addition, comparison of system energy consumption under two different static pressure control method is carried out, i.e. controlled by frequency conversion fan and static pressure control unit. Result shows that power consumption of refrigeration compressor under two different static pressure control strategies only has a slight difference. The main difference lies in power consumption of blower. And as operation time of VAV A/C system is prolonged, total power consumption is continuously increased. From the perspective of power consumption, VAV A/C system whose supply air static pressure is controlled by frequency conversion fan can achieve the aim of energy saving better. However, when adopting static pressure control unit to control supply air static pressure, the initial investment is less than the other method. Therefore, comprehensive economic benefit should be taken into account when designing a marine VAV A/C system.

Summarizing the work of this paper, the research on marine VAV air conditioning system should continue in the following aspects:

1) When using the static pressure control unit to control the static pressure of the air duct, there is no discussion on energy consumption analysis and system stability of setting the opening of the bypass ventilation valve at other positions. In the future study, the setting value of the opening of the bypass ventilation valve should be studied in depth to investigate the operation of the system .

2) The thermal expansion valve was used as the throttling mechanism to control the super-heat when studying the air supply control control system of Marine VAV air conditioning system. Electronic expansion valve because of its fast speed and wide range of regulation, with reasonable control methods can achieve a good quality of super-heat regulation. Therefore, in the future work, the operation characteristics and air supply control system of Marine VAV air conditioning system with electronic expansion valve as throttling mechanism should be studied.

\section{Acknowledgment}

The research of this paper is supported by Foundation of Shandong Educational Committee (No. J18KA043) and Shandong Jiaotong University Municipal Natural Science Foundation (No. Z201333).

\section{References}

[1] Chen, W., Zheng, C., Lei, Y., Liu, S., et al. (2012). Research on the control of marine direct-expansion variable-air-volume (VAV) air-conditioning (A/C) system. Ship Engineering, 34(1), 43-46.

[2] You, C., \& Liu, W. (2000). Feasibility analysis of VAV technology application to marine air-conditioning. Shipping, 1, 33-36.

[3] Guo, J., Chen, W., Cai, Z., et al. (2009). Discussion on the application of variable-air-volume air conditioning system on ships. Proceedings of the 6th International Symposium on Heating, Ventilating and Air Conditioning Conference (pp. 413-418).

[4] Yu, B. (2005). New Technologies of Centralized Air-Conditioning System. Beijing: Chemical Industry Press.

[5] Chen, Z. (2016). The energy efficiency design in variable air volume system. Green Building, 3, 18-21.

[6] Liu, E.-H., Jiang, Y.-Y., Pan, J.-X., et al. (2017). Energy saving design and study on shipboard air-conditioning system. Energy Conservation, 2(1), 36-38.

[7] Chen, W., Deng, S., Cai, Z., et al. (2005). Dynamic simulation of VAV air conditioning systems and control of supply fans. $H v \& A c, 35(8), 104-109$.

[8] Li, L. J., \& Dong, Z. X. (2018). Research on temperature control of subway station based on BP neural 
network PID. Journal of Tianjin University of Technology, 34(5), 9-13.

[9] Lei, Y. J. (2011). Research on Control Method for the Marine VAV Air-Conditioning System. Xia Men: Jimei University Press.

[10] Hartman, T. (1993). Terminal regulated air volume (TRAV) systems. ASHRAE Transactions, 99(1), 791-800.

[11] Han, H. (1999). Energy saving studies of variable frequency air conditioning fans for marine air conditioning. Navigation Of China, 44(1), 51-55.

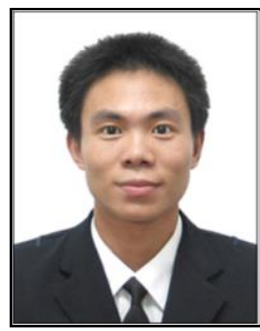

Junjie Guo received the degree in the marine engineering from Jimei University, China, in 2007. He has been teaching in the fields of marine engineering since 2010 and is one of the founder members of the Department. Now he is engaged in the research of marine engineering management, air conditioning control and so on. 